\title{
Bacterial Respiratory Infections Complicating Human Immunodeficiency Virus
}

\author{
Charles Feldman MB BCh, DSc, PhD ${ }^{1}$
}

Ronald Anderson PhD ${ }^{2}$

\begin{abstract}
${ }^{1}$ Division of Pulmonology, Department of Internal Medicine, Charlotte Maxeke Johannesburg Academic Hospital and Faculty of Health Sciences, University of the Witwatersrand, Johannesburg, South Africa

${ }^{2}$ Institute of Cellular and Molecular Medicine, Department of Immunology, Faculty of Health Sciences, University of Pretoria, Pretoria, South Africa
\end{abstract}

Address and correspondence:

Professor Charles Feldman

Department of Internal Medicine

University of the Witwatersrand

Medical School

7 York Road, Parktown, 2193

Johannesburg

South Africa

Tel: $011488-3840$

Fax: 011 488-4675

e-mail: charles.feldman@wits.ac.za

\begin{abstract}
Opportunistic bacterial and fungal infections of the lower respiratory tract, most commonly those caused by Streptococcus pneumoniae (the pneumococcus), Mycobacterium tuberculosis, and Pneumocystis jirovecii, remain the major causes of mortality in those infected with human immunodeficiency virus (HIV). Bacterial respiratory pathogens most prevalent in those infected with HIV, other than $M$. tuberculosis, represent the primary focus of the current review with particular emphasis on the pneumococcus, the leading cause of mortality due to HIV infection in the developed world. Additional themes include: i) risk factors; ii) the predisposing effects of HIV-mediated suppression on pulmonary host defenses, possibly
\end{abstract}


intensified by smoking; iii) clinical and laboratory diagnosis, encompassing assessment of disease severity and outcome; and iv) antibiotic therapy. The final section addresses current recommendations with respect to pneumococcal immunization in the context of HIV infection, including an overview of the rationale underpinning the current "prime-boost" immunization strategy based on sequential administration of pneumococcal conjugate vaccine 13 (PCV13) and pneumococcal conjugate vaccine 23 (PPV23).

Keywords: community-acquired pneumonia; host defenses; outcome; pneumococcal immunization; pneumococcus; risk factors; severity of illness; treatment.

\section{Introduction}

It has been well recognized for a number of years that the lung is the site most severely affected as a consequence of human immunodeficiency virus (HIV) infection and most patients with HIV infection will develop a pulmonary complication during the course of their illness, of which pulmonary infections predominate [1, 2]. Bacterial pneumonia is still not infrequently the first clinical manifestation of the presence of HIV infection in a patient [1]. There have, however, been significant changes in the epidemiology of pulmonary infections in HIV-infected persons over the years, initially as a consequence of the use of prophylaxis for Pneumocystis pneumonia (PCP) and subsequently the introduction of highly active anti-retroviral therapy (HAART) [2-4]. Currently, bacterial pneumonia, and especially communityacquired pneumonia (CAP) due to Streptococcus pneumoniae, is the most common respiratory infection in HIV-infected patients in the developed world, followed by PCP and tuberculosis (TB), while TB is the predominant complication in the developing world, followed by CAP [2]. The incidence of CAP has been said to be up to 35-fold higher in HIV-infected individuals, compared with HIV-uninfected persons of similar age, and although the incidence has decreased in the former patients with the use of HAART, it still remains higher than in HIV-uninfected persons [3]. Thus, despite significant advances in the management of patients with HIV infection, CAP still remains a cause of considerable morbidity and mortality in both the developed and 
developing worlds, and the pneumonia per se has also been recognized to have a significant impact on both the progression of HIV disease and its outcomes [3, 4].

The topic of this review, viz. HIV and bacterial infections of the lower respiratory tract, has been covered by us in two previous reviews $[5,6]$. The current review therefore represents an update, encompassing not only an overview of the major causative bacterial pathogens, but also incidence and risk factors, as well as the predisposing role of HIV-mediated suppression of pulmonary host defenses exacerbated by cigarette smoking. Additional topics include laboratory diagnosis, clinical strategies in the assessment of disease severity and outcome, and, finally, preventive strategies, particularly pneumococcal immunization and the rationale underpinning the current "prime-boost" vaccination strategy.

\section{Community-acquired bacterial pneumonia}

Overall, bacterial pneumonia is currently the leading cause of pulmonary infection in HIV-infected patients throughout the world, with variations in incidence in different parts of the world being related to the geographical location and the prevalence of specific additional risk factors in the patents [2].

\section{Incidence}

Much has been written about the incidence of CAP in HIV-infected patients with a suggestion from a peer review of the literature that these infections may be up to 25fold more common in in HIV-infected patients than in the general community, occurring in up to 90 cases per 1,000 person-years [7]. While higher and lower rates than this have been documented in different studies [4], it is interesting to note that a study among a cohort of former injection drug users, including cases with and without HIV infection, documented a similar rate of CAP of 90.5 per 1000 personyears in the HIV-infected group [8], and a study in the HAART era among HIVinfected women, with a history of either intravenous drug use and/or risky sexual behaviour, documented a similar rate of 8.5 cases per 100 person-years [9]. 
Clearly, variations in the reported incidences and rates of CAP in the individual studies may relate not only to different time periods in the HIV pandemic, but also to the availability of various forms of prophylaxis and/or antiretroviral therapy, as well as to differing additional risk factors for CAP in the study populations [4]. One study from a single center in the Unites States (US), undertaken to determine whether there was a change in the spectrum of HIV-associated lung diseases since the introduction of HAART, noted that while PCP was less common in the HAART era, bacterial pneumonia was more common $(\mathrm{OR}, 2.41 ; \mathrm{Cl} 1.12$ to 5.17) [10]. This is in contrast to the study by Sullivan and colleagues that showed a dramatic decrease in the incidence of bacterial pneumonia following use of antiretroviral therapy, including protease inhibitors [11]. However, these studies are not directly comparable at least in the respect that the former study included both hospital- and community-acquired bacterial pneumonias, and the latter only community-acquired infections. The authors of the former study also acknowledge that their findings really reflect a decrease in opportunistic infections rather than a direct increase in the occurrence of bacterial pneumonia [10]. Overall, therefore, it is recognized that while rates of pneumonia have been shown to decrease with use of cotrimoxazole prophylaxis and introduction of HAART, the incidence of CAP in HIVinfected patients still remains higher than in HIV-uninfected individuals [2, 4, 9].

\section{Risk factors}

A myriad of articles has documented the risk factors for CAP/bacterial pneumonia in HIV-infected patients, over and above the risk from HIV per se and are shown in Table 1 [1-4, 9-16]. While HIV infection itself is known to be a risk factor for bacterial CAP, the exact mechanisms associated with this enhanced risk are incompletely understood and are currently being investigated [15]. Older age, and in some studies male gender, have been documented to be additional risk factors for bacterial pneumonia in HIV-infected patients $[2,16]$. It has also been suggested that there is a difference in the risk of bacterial pneumonia in different ethnic groups with HIVinfection, possibly attributable to genetic differences [4, 7]. Markers of low socioeconomic status have also been shown to be associated with an increased risk of bacterial CAP $[7,9,17]$. Furthermore, those in close contact with children, such as care-givers of young children and even HIV-infected mothers of young children may 
Table 1: Risk factors for, and factors protective against, CAP/bacterial pneumonia in HIVinfected patients

\section{Protective factors}

- HIV infection per se

- Age

- Co-trimoxazole prophylaxis

- Socioeconomic status

- HAART

- Gender differences

- Higher CD4 cell counts

- Ethnic differences

- Suppressed HIV viral loads

- Care giver to young children / mothers

- Pneumococcal vaccination

- Smoking of cigarettes and illicit drugs

- Injection drug use

- Alcohol abuse

- Malnutrition

- Low CD4 cell count

- Unsuppressed viral load

- Neutropenia

- Comorbid conditions

- Prior episode of pneumonia

- Previous episode of PCP

be at increased risk of pneumonia due to high rates of nasopharyngeal carriage of pneumococcal organisms in the children [4, 7].

While CAP in HIV-infected persons may occur at any level of immunosuppression, it has been well characterized that the risk increases with decreasing CD4 cell counts, and is greatest once the CD4 cell count falls below 200 cells/ $\mu \mathrm{l}[1-4,7,11-13]$. High and/or unsuppressed and/or detectable HIV viral loads have also been shown to increase the risk of pneumonia $[2,4,16]$. Neutropenia, which may result from a number of factors in HIV-infected persons, including HIV infection per se, or even antiretroviral therapy, is a risk factor for bacterial lower respiratory tract infections [1]. 
Many studies have documented the fact that injection drug use is associated with an increased pneumonia risk in HIV-infected persons, and while this may be due to associated confounding factors, such as socioeconomic conditions and adherence to therapy, there is some evidence that some of the risk may be due to direct drug effects in some cases, or even to the effects of drug withdrawal [3, 4, 7, $11,13,14]$. Similarly alcohol abuse has been reported to be associated with a high incidence of bacterial CAP [14]. The role of smoking as a major risk factor is addressed more fully below.

A number of studies have documented that a previous episode of pneumonia or PCP appears to be a risk factor for CAP $[1,10,11,13,18]$. There are additional risk factors for bacterial pneumonia in HIV-infected persons, including various underlying comorbid conditions, a low Karnovsky score, and elevated baseline systemic inflammatory markers (C-reactive protein, interleukin 6 and D-dimers), but not pulmonary specific markers of inflammation (club cell secretory protein 16 and surfactant protein D) $[1,7,19]$.

With regard to a decreased risk of bacterial pneumonia, co-trimoxazole prophylaxis has been shown, at least in some studies, to be associated with a lower risk of bacterial infections such as pneumonia, in one study being associated with a $67 \%$ reduction in the occurrence of confirmed cases of bacterial pneumonia $(p=0.007)[9,12,18]$.

HAART has been shown to decrease the risk of bacterial pneumonia [2, 9]. However, it has been said that the greatest benefit may be on hospital-acquired rather than community-acquired infections [2]. In one study, a combined antiretroviral regimen containing a protease-inhibitor was associated with a significantly lower risk of bacterial pneumonia (Risk ratio [RR] $0.55,95 \% \mathrm{Cl} 0.31-0.94$ ) [11]. Although studies have shown that continuous rather than intermittent antiretroviral therapy has a greater impact on the risk of pneumonia [2, 4], others have documented that viral suppression is associated with a lower incidence of pneumonia [4]. 
In contrast to the reduction in risk of pneumonia, as well as improved outcome following an episode of pneumonia, reported in HIV-uninfected patients taking regular statins, these benefits of statins are not evident in HIV-infected patients [4].

\section{HIV-mediated suppression of pulmonary host defenses}

The impact of HIV infection on susceptibility to bacterial infection, including that caused by bacterial respiratory pathogens, has been addressed extensively in several recent reviews [20-22] and is covered only briefly here. In apparent contrast to the gastrointestinal tract, which undergoes rapid and extensive depletion of the memory $\mathrm{T}$ cell subset in particular, the diverse host defenses of the lungs appear more resilient in the face of this early HIV-mediated onslaught [22]. In spite of this, pulmonary host defenses are progressively weakened and eventually subdued, resulting in HIV-mediated severe impairment of adaptive primary and memory immune responses, as well as recruitment and activation of innate effector cells which are dependent on these specific immune mechanisms. The consequence is heightened susceptibility to infection by a range of respiratory bacterial pathogens, especially Streptococcus pneumoniae (the pneumococcus) and Mycobacterium tuberculosis [2]. Together with the fungus, Pneumocystis jirovecii, these two bacterial pathogens account for approximately $75 \%$ of serious pulmonary infections in HIVinfected individuals, with the relative frequencies of each pathogen varying according to geographic region as mentioned above [2].

The following are the major HIV-mediated abnormalities of pulmonary immune function which predispose to infection with bacterial respiratory pathogens:

- destruction of $\mathrm{CD}^{+}{ }^{+} \mathrm{T}$ cells by several mechanisms including: i) direct cytopathic effects of HIV; ii) recognition of surface expressed viral antigens by CD8 ${ }^{+}$ cytotoxic T cells; iii) chronic exposure to apoptosis-inducing viral antigens; and iv) chronic immune activation with sustained exposure to pro-apoptotic cytokines generated by cells of both the adaptive and innate immune systems [22] 
- susceptibility of a subset of $\mathrm{CD} 4^{+} \mathrm{T}$ cells known as follicular helper T cells (Tfh) to HIV infection. These cells are found in the B cell follicles of secondary lymphoid organs, where they initiate and maintain germinal centers, driving antibody production [23]. Tfh cells appear to be particularly receptive to HIV infection, supporting efficient replication and production, as well as promoting persistence by acting as a reservoir for HIV [23].

- persistence of counteracting endogenous anti-inflammatory strategies to control chronic immune activation. These include sustained production of antiinflammatory cytokines such as interleukin (IL)-10 and transforming growth factor- $\beta 1$ generated by various cell types and mechanisms, as well as induction of immunosuppressive regulatory T cells [22]. Unwittingly, however, these also contribute to increased susceptibility for development of microbial infection.

- apparent selective infection and phagocytic dysfunction of a discrete subset of macrophages known as small alveolar macrophages [24], as opposed to large alveolar macrophages which retain normal phagocytic function [25]. Phagosomal proteolytic activity, on the other hand, is defective in both types of alveolar macrophage irrespective of HIV infection of these cells [24].

- neutropenia is commonly found in patients with advanced HIV infection [21] and may contribute to the heightened susceptibility for development of pneumonia and caused by several bacterial pathogens, including Staphylococcus aureus in particular, as well as the pneumococcus and various types of gram-negative pathogen.

While heightened susceptibility for development of pulmonary tuberculosis can be attributed predominantly to HIV-mediated severe impairment of cell-mediated immune mechanisms, in other cases, such as that of the pneumococcus, abnormalities of both cell-mediated and humoral immunity are contributory [26]. 


\section{Smoking and pulmonary host defenses}

HIV-infected smokers appear to be particularly susceptible to the adverse health effects of the smoking habit. This increased risk, which persists following administration of virally-suppressive HAART, encompasses not only lung infections, but also non-AIDS-defining conditions, including pulmonary, cardiovascular, and neoplastic disorders [22, 27-30]. Even in the setting of access to reliable health care, HIV-infected smokers lose more life-years to the smoking habit, than to HIV infection per se [31].

Smoking, like HIV infection also compromises pulmonary immune function [32]. However, very few studies have addressed the important topic of the probable, interactive, adverse effects of HIV infection and smoking on susceptibility to serious infection with bacterial respiratory pathogens. Unlike HIV infection, however, the predisposing effects of smoking for development of bacterial pulmonary infection are operative at the levels of both the pathogen and the host. In the case of bacterial pathogens, flakes of cured tobacco, which are inhaled during smoking, contain many different potential bacterial pathogens [33]. Chronic exposure of smokers to these tobacco-associated microbes, together with cigarette smoke-mediated suppression of airway host defenses, may underpin alterations in the nasopharyngeal microbiota of smokers which are characterized by replacement of commensal bacteria with potential pathogens such as the pneumococcus, $S$. aureus, and non-typeable Haemophilus influenzae [34, 35]. Exposure to cigarette smoke has also been reported to enhance the virulence and persistence of these pathogens via upregulation of expression of bacterial adhesins and production of protective biofilm respectively [36-38].

The suppressive effects of smoking on airway innate and adaptive host defences are well documented and have recently been described in detail elsewhere [32]. These include interference with the protective activities of the mucociliary escalator, alveolar macrophages, dendritic cells, natural killer cells (NK), T lymphocytes and B lymphocytes, due in large part to chronic exposure to the vast array of cytotoxins present in cigarette smoke [32]. Like HIV infection, smoking has also been reported to cause dysregulation of pulmonary cytokine networks, creating 
a chronic inflammatory milieu conducive to immunosuppression. This is nicely illustrated by the findings of two very recent studies.

In the first of these, prior experimental exposure of mice to cigarette smoke resulted in exacerbation of airway inflammatory responses following induction of experimental viral infection [39]. The pro-inflammatory effects of cigarette smoking in this experimental setting were attributed to altered expression of the IL-33 receptor, ST2, on cells of the innate pulmonary immune system. ST2 was found to be downregulated on "anti-inflammatory" type 2 innate lymphoid cells, and up-regulated on pro-inflammatory macrophages and NK cells, thereby amplifying inflammatory responses [39]. In the second study, exposure of both mice and humans to cigarette smoke resulted in decreased concentrations in alveolar lining fluid of the antiinflammatory proteins, suppressors of cytokine signaling (SOCS), SOCS1 and SOCS3 [40]. These are contained in exosomes (SOCS1) and microparticles (SOCS3) released by alveolar macrophages, which, in turn, are internalized by alveolar epithelial cells, resulting in suppression of cytokine signaling, an antiinflammatory mechanisms which is attenuated by smoking [40].

In addition, cigarette smoke has several pro-infective effects on airway epithelial cells. These include i) up-regulated expression of the platelet-activating factor (PAF) receptor on lower airway epithelial cells, thereby promoting adherence of the pneumococcus via binding to cell-wall phosphorylcholine [41]; and ii) disruption of epithelial tight functions and barrier integrity, favouring extra-pulmonary dissemination of bacterial respiratory pathogens [42].

The pro-infective effects of cigarette smoking on both the pathogen and the host are summarized in Table 2. 
Table 2: Pathogen- and host-targeted pro-infective effects of cigarette smoking

\begin{tabular}{|c|c|}
\hline Pathogen & Host \\
\hline $\begin{array}{l}\text { - Chronic exposure to pathogen-contaminated } \\
\text { cured tobacco [33] }\end{array}$ & $\begin{array}{l}\text { - Suppression of innate and adaptive airway } \\
\text { host defences [32] }\end{array}$ \\
\hline $\begin{array}{l}\text { Transition from a commensal- to a pathogen- } \\
\text { dominant nasopharyngeal microbiota }[34,35]\end{array}$ & $\begin{array}{l}\text { - Creation of a pro-inflammatory pulmonary } \\
\text { milieu due to redistribution of expression of } \\
\text { ST2 on cells of the pulmonary innate immune } \\
\text { system, as well as attenuation of the release } \\
\text { of SOCS1 and SOCS3 from alveolar }\end{array}$ \\
\hline - Increased expression of bacterial adhesins & macrophages $[39,40]$ \\
\hline - Induction of biofilm formation $[36,37]$ & $\begin{array}{l}\text { - Increased expression of the PAF receptor on } \\
\text { airway epithelium and disruption of the } \\
\text { alveolar epithelial barrier promoting } \\
\text { adherence and dissemination of airway } \\
\text { pathogens respectively }[41,42]\end{array}$ \\
\hline
\end{tabular}

References in parentheses

\section{Respiratory tract microbiome}

Clearly, HIV- and smoking-mediated suppression of pulmonary host defenses would be expected to have a significant impact on the pulmonary microbiome, which, in turn, may exacerbate immune dysfunction. However, relatively few studies have addressed the issue of alterations in the lung microbiome which accompany HIV infection and their possible impact on pulmonary function and host defense. Of the few studies published to date, molecular analyses have revealed over-representation of the gram-positive bacterium, Tropheryma whipplei, the causative agent of Whipple's disease, and the fungus Pneumocystis jirovecii in the bronchoalveolar lavage fluid of asymptomatic, HIV-infected individuals relative to uninfected subjects $[43,44]$. Virally-suppressive antiretroviral therapy resulted in attenuation of colonization of the lung by $T$. whipplei [43]. In the latter study, over-representation 
with $P$. jirovecii was also detected in the lungs of HIV-infected patients with chronic obstructive pulmonary disease, possibly consistent with etiologic involvement of the fungus, either directly or indirectly, in HIV-associated pulmonary dysfunction [44].

In the case of cigarette smoking, the lung, as opposed to the oral, microbiomes of healthy non-smokers and smokers do not differ significantly [45], while similar studies in HIV-infected non-smokers and smokers have not been described to date.

\section{Causative organisms}

In general, the bacterial organisms causing CAP in HIV-infected persons are very similar to those in HIV-uninfected cases [4]. As in the general population, Streptococcus pneumoniae is the most common cause of bacterial CAP in HIVinfected patients, accounting for approximately $20 \%$ of cases overall and $40 \%$ of those cases in which a microorganism is isolated [2]. The next most common cause is said to be Haemophilus influenzae, which accounts for some $10-15 \%$ of cases of bacterial CAP, followed by Staphylococcus aureus [2]. Infections with Pseudomonas aeruginosa appear to be much less common in the HAART era [2]. In general, infections with the so-called atypical pathogens appear to be relatively less common [2], while infections with Rhodococcus equi and Nocardia are also uncommon [2].

\section{Streptococcus pneumoniae}

A number of studies clearly attest to the fact that HIV infection is a particular risk factor for pneumococcal pneumonia and other pneumococcal infections [46, 47]. An exceedingly high risk for invasive pneumococcal disease (IPD) exists in HIV-infected patients [47-49], which appears to be 30-100 times greater than in HIV-uninfected patients of similar age [47]. For example, in one study the incidence of IPD in healthy adults was 8.8 per 100,000 persons, whereas in patients with HIV/AIDS it was 422.9/100,000 persons [48]. The incidence of IPD appears to be highest among injection drug users who are HIV-infected [49] and recurrent episodes of IPD are also more common in HIV-infected persons [47, 49, 50]. Other studies have also documented a higher incidence of pneumococcal disease (pneumonia and IPD) in injection drug users [51]. One study suggested that HIV-infected patients with CAP 
who were not on HAART and had a positive pneumococcal urine antigen test were more likely to have bacteremia [52]. Another reported that HIV-infected patients with comorbid conditions, high viral loads, and low CD4 cell counts were at higher risk of developing IPD [53]. Other studies have also documented that a lower CD4 cell count is a risk for both pneumococcal pneumonia and IPD [51]. These authors reported a decreased risk for pneumococcal disease following use of antiretroviral therapy and pneumococcal vaccination [51]. Another study comparing patients with bacteremic and non-bacteremic pneumococcal CAP, documented, among other risk factors, that those who were bacteremic were more likely to be HIV-infected [54]. Importantly it is suggested that adults with IPD who are 15-44 years of age with no other apparent risk factors should be tested for HIV infection [55].

With regard to the clinical features of pneumococcal pneumonia in HIVinfected patients, additional risk factors include cigarette smoking, intravenous drug use, a low CD4 cell count $<200$ cells $/ \mu$ and alcohol abuse [56]. While the clinical presentation of pneumococcal pneumonia in HIV-infected patients may be similar to that of HIV-uninfected patients, it is said that unusual presentations may occur depending on the degree of immunosuppression [56]. In one study of bacteremic pneumococcal pneumonia, comparing HIV-infected and-uninfected cases, the former patients tended to have respiratory symptoms (cough, sputum production, hemoptysis, pleuritic chest pain), and systemic symptoms (rigors, diarrhea, vomiting, headache) more commonly [57]. Radiological features may vary and besides a classical lobar consolidation, bilateral infiltrates may occur [56,57]. With regard to the outcome of IPD when comparing HIV-infected and HIV-uninfected patients, some studies suggested there was no difference in mortality when comparing these two groups of patients. However, in one large, multicenter, international study, when cases were stratified according to age and severity of illness, the 14-day mortality from IPD was higher in HIV-infected patients and tended to greater as the CD4 cell count decreased [57]. This is described more fully below.

With regard to some of the microbiological features of pneumococcal infection and IPD, it is firstly recognized that in HIV-infected patients pneumococcal infections can occur concomitantly with other infections, with dual infection with $S$. pneumoniae and $M$. tuberculosis being documented in one study [58]. Documentation of 
additional infections is crucial for the appropriate management of these patients and while all the cases of pneumococcal infection were documented on the basis of positive blood cultures, some of the cases required bronchoscopy to confirm the additional diagnosis of TB [58]. With regard to pneumococcal serotypes, studies have been documenting the emergence of serotype 8 , a serotype not contained in the current conjugate pneumococcal vaccines, particularly among cases with IPD $[59,60]$. The importance of this serotype is its expression of resistance to a number of antimicrobial agents, commonly including levofloxacin [59,60].). Furthermore, use of cotrimoxazole prophylaxis against PCP has been associated with a higher incidence of infections with antibiotic resistant IPD isolates, at least in some studies [49]. Interestingly, one study investigating antibiotic resistance in $P$. aeruginosa and S. pneumoniae in HIV-infected patients in the HAART era documented that use of HAART reduced the number of antibiotic resistant pseudomonal pneumonia cases, but not pneumococcal pneumonia cases [61].

There have been a considerable number of studies and reviews published describing the impact of introduction of HAART on the incidence of IPD [3, 47, 49, 62-67]. While studies from the US and other parts of the developed world have shown significant and sharp decreases in the incidence since the introduction of HAART $[49,63,64]$, it is important to be aware that the incidence is still some 35 -fold higher in HIV-infected persons than in HIV-uninfected cases of similar age $[3,47]$. One study from South Africa documented that despite a stable prevalence of HIV infection and a progressive roll-out of HAART, the burden of IPD had not decreased in HIV-infected adults, thus highlighting not only the importance of monitoring HIV disease and the impact of the HAART program, but also to consider alternative strategies, particularly the use of the pneumococcal conjugate vaccine [66]. Another study documented a relatively stable incidence of IPD over the study period 19962002, which includes the modern HAART era [62], and a third documented that despite widespread use of HAART and the 23-valent pneumococcal vaccine that the incidence of IPD remained high in HIV-infected patients, with its associated morbidity and mortality [65]. 


\section{Haemophilus influenzae}

Infections with Haemophilus spp., and particularly Haemophilus influenzae, have been documented in patients who are HIV-infected, causing either pneumonia, or bacteremia, with or without pneumonia [68-73]. The most recent study of $H$. influenzae pneumonia in HIV-infected patients documented 26 cases over a 12 month period, most of whom were severely immunocompromised with $73.1 \%$ of them having a CD4 cell count below 100 cells/ $\mu$ l [73]. Previous studies have suggested that injection drug use is a particular risk factor for $\mathrm{H}$. influenzae pneumonia and in the current study there was a high proportion of such individuals. The study documented that while the presentation of the infection may be typical of other pyogenic pneumonias presenting acutely with cough, purulent sputum and dyspnoea, some patients present with a subacute illness, and more than half present with a bilateral lung infiltrate, rather than a lobar/alveolar consolidation, thus more closely resembling PCP infection $[69,73]$. Thus the clinical features do not reliably suggest the diagnosis of $H$. influenzae pneumonia, which has to be considered as a possible cause of pneumonia in HIV-infected patients, especially in the setting of advanced immunocompromize [73], and some patients present with coexisting infections, including PCP [68]. The mortality rate for $\mathrm{H}$. influenzae infections in HIVinfected persons is the same as that with such infections in the general population [73], although relapses can occur following antibiotic therapy [69].

The largest study documenting Haemophilus spp., bacteremia in adults, some of which were nosocomial, noted that HIV infection was the most common underlying risk factor and that the HIV-infected patients were more frequently younger and presented more commonly with pneumonia than those that were HIV-uninfected [72]. The mortality rate in that study was higher, at $22 \%$, although HIV infection itself did not appear to be an independent risk factor and the authors indicated the need to take into account possible antimicrobial resistance when choosing antibiotic therapy.

\section{Staphylococcus aureus}

It is not uncommon for isolates of Staphylococcus aureus to be cultured from respiratory tract specimens in HIV-infected patients presenting with respiratory 
disease, which may represent colonization, or be of indeterminate significance, or be associated with S. aureus pneumonia (SAP) [74]. SAP appears to be mainly community-acquired and the presentation may be acute or subacute $[74,75]$. The patients commonly present with typical symptoms including fever, cough, chest pain and dyspnea, and have clinical features of pneumonia on examination [74, 75]. Predisposing factors to SAP include intravenous drug abuse and previous PCP, but underlying concomitant pulmonary disorders are commonly present in the patients $[74,75]$. The chest radiograph usually shows a lobar pneumonia/local infiltrates, especially in the lower lobes, but consolidation with cavitation, and interstitial-nodular infiltrates also occur $[74,75]$. Pleural effusions are quite common in patients with SAP [75]. Additionally some of the earlier studies of HIV-infected patients with CAP documented parapneumonic effusions to be more common than in HIV-uninfected patients and noted $S$. aureus to be the most common cause [76], although more recently the pneumococcus may be more common. When SAP is suspected or documented, specific antibiotic therapy is clearly indicated. The mortality of SAP has been relatively high in the different studies (e.g. $21 \%$ in the study by Tumbarello and colleagues) and has been associated with advanced immunosuppression and recurrent pneumonia [75]. Community-acquired methicillin resistant Staphylococcus aureus (CA-MRSA) pneumonia has been described more recently, which has been characterised by the presence of necrotizing features, and cases have been documented in HIV-infected patients [77]. In one series, the mortality was lower than previously described, which the authors attributed to the possible greater use of antibiotics (clindamycin or linezolid) that inhibited endotoxin production or the presence of nontoxigenic strains [77]. At least one case of Panton-Valentine leucocidin-producing $S$ aureus pneumonia has been documented in an HIV-infected patient, associated with a poor outcome [78].

\section{Atypical pathogens}

Although studies have documented the presence of so-called atypical pathogens (Legionella pneumophila, Chlamydia pneumoniae, Mycoplasma pneumoniae) as causes of pneumonia in HIV-infected persons, the true prevalence of these pathogens in this setting is uncertain [79]. Considering that basing the diagnosis of these infections on serological testing may not be accurate since antibody responses 
may be compromised in AIDS patients, Tarp and colleagues applied polymerase chain reaction (PCR) analyses for Chlamydia spp., Legionella spp., and Mycoplasma pneumoniae to consecutively obtained bronchoalveolar lavage (BAL) specimens obtained from HIV-infected patients with pneumonia. L. pneumophila was detected in $1 \%$ of BAL fluids, M. pneumoniae was documented as a coexisting pathogen in $2 \%$ and Chlamydia spp., could not be detected [79]. The authors concluded that while these pathogens may be uncommon as causes of pneumonia in HIV-infected persons, they should be considered as possible causes in cases with treatment failure.

A number of authors concur that Legionnaire's disease has been infrequently described in HIV-infected patients [80]. Part of the reason for this may be due to the use of co-trimoxazole prophylaxis against PCP, since this agent has good activity against Legionella and a similar case may be made in the case of the use of azithromycin prophylaxis for non-tuberculous mycobacteria [80]. Another reason may be that Legionella infections may occur concurrently with other pneumonias, including PCP, and of these the former is the one that is difficult to document [80]. Other authors have documented the occasional occurrence of Legionnaire's disease in HIV-infected patients and suggested that it may be associated with a more severe presentation [81]. There does not appear to be an association between Legionella infection and any particular level of the CD4 cell count [80, 81]. A case of Legionella pneumophila pneumonia in an HIV-seropositive patient with significant neurological manifestations, which are not uncommon in Legionellosis, has been reported more recently [82].

Chlamydia pneumoniae pneumonia has been described not uncommonly in HIV-infected patients [83, 84]. Infection appears to be associated with both a low CD4 cell count and high viral loads [84]. It also appears to be associated with hyperlipidemia and might represent an additional risk factor in HIV-infected patient [84]. While patients may develop focal pneumonia, others may develop diffuse interstitial pulmonary involvement and even respiratory failure [83]. Chlamydia pneumoniae may be the sole pathogen causing pneumonia in HIV-infected patients, but can also be found together with other pathogens [83]. It has been suggested that this pathogen should always be suspected as possible cause of pneumonia in HIV- 
infected patients with pneumonia who are not responding to standard beta-lactam or PCP therapy [83].

One study documented a relatively high prevalence of M. pneumoniae in HIVinfected patients with respiratory tract symptoms, higher than that occurring among HIV-uninfected cases and this pathogen should be considered as a possible cause of atypical respiratory infections [85].

\section{Pseudomonas aeruginosa}

A number of studies and reviews attest to the fact that HIV-infected patients are at increased risk of $P$. aeruginosa infections, especially pneumonia, including both community-acquired and nosocomial infections [86-92]. For example, one prospective, observational study designed to document the organisms causing bacterial pneumonia in hospitalized patients with HIV infection reported that $P$. aeruginosa was the most common cause, accounting for 32 of the recorded 111 admissions [88]. Community-acquired infections were much more common than nosocomial infections, as has also been documented in many of the other studies $[86,88,89]$. This study and others have documented that pseudomonal infections occur in cases with advanced HIV disease, in association with low CD4 cell counts [86-89]. In this study when compared to the cases with pneumococcal infection, the patients with pseudomonal pneumonia, in addition to having a lower CD4 cell count, also had a longer length of hospital stay, but a similar mortality [88]. While in some studies no additional risk factors other than HIV infection have been present, other studies have noted use of PCP prophylaxis, broad spectrum antibiotics, and corticosteroids as additional risk factors for pseudomonal infections [86-88]. With regard to the clinical presentation of the respiratory infections, one study documented two patterns of disease, namely a sepsis syndrome with a fulminant course, or an indolent course, with some of the latter cases relapsing after apparent successful treatment [86]. Some authors have documented resolution of these recurrent/persistent infections in patients initiated on antiretroviral therapy with immune reconstitution [91]. Varying radiological patterns were also noted in that study, including an interstitial pattern mimicking PCP, lobar pneumonia and bronchial 
wall thickening [86]. Cavitating pneumonia may also occur. It appears that $P$.aeruginosa pneumonia is less common in the HAART era [92].

\section{Rhodococcus equi}

Although an uncommon cause of human infection, quite a large number of cases of pneumonia due to Rhodococcus equi have been documented in HIV-infected patients [93]. Most patients have had more advanced immunosuppression [93]. While the lung is the most common site infected by this organism, other manifestations of infection can occur, including bacteremia and brain abscesses [93]. The most common presentation in the lung is that of focal cavitating pneumonia [93]. Bilateral pulmonary involvement and the occurrence of pleural effusions have been documented [93]. The isolated strains have varying antimicrobial susceptibility [93]. Although the optimal treatment of these infections is uncertain, it appears that combination antibiotic therapy and early initiation of HAART appears to be associated with the best outcome [93].

\section{Moraxella catarrhalis}

Moraxella catarrhalis has been described as a cause of pneumonia and of bacteremia in HIV-infected patients [94]. Concomitant infections with other respiratory pathogens, including S. pneumoniae and M. tuberculosis have also been noted [94].

\section{Laboratory diagnosis}

In the case of severe disease in both HIV-infected and -uninfected patients, traditional microbiological laboratory procedures for the detection of putative bacterial respiratory pathogens in body fluids are used to complement clinical and radiological investigations. Although useful, traditional microbiological procedures have significant limitations, particularly in the case of fastidious slow-growing organisms, resulting in prolonged time to both pathogen identification and antibiotic sensitivity. These limitations have resulted in the development of innovative, rapid, diagnostic tests based on the detection of bacterial antigens and/or nucleic acid in 
body fluids. In the case of the former, Binax NOW® immunochromatographic procedures are often used to detect the presence of the C-polysaccharide cell-wall component of the pneumococcus, which is common to all serotypes [95].This type of procedure is also used to detect Legionella pneumophila serotype 1 antigen and has recently been adapted to enable simultaneous detection of both pathogens [96].In the case of invasive pneumococcal disease, Binax NOW® can be used in combination with, or may even eventually be replaced by, multiplex capsular polysaccharide antigen detection assays. This strategy enables rapid serotype identification, which is of importance not only in respect of epidemiology and surveillance, but also in monitoring vaccine efficacy [97-99]. Additional antigen detection tests, of which several are available, include the Pneumotest-Latex procedure, also based on detection of pneumococcal capsular polysaccharides. Originally developed for improved serotyping/serogrouping [100], this procedure has also been found to have diagnostic potential, demonstrating a level of $88.1 \%$ agreement with a molecular PCR-based diagnostic method [101].

Quantitative RT-PCR-based detection of pneumococcal nucleic acid, in biological fluids, often combined with simultaneous detection of antibiotic resistance genes, is currently the method of choice for rapid diagnosis of pneumococcal infection. Of several genes investigated, including those encoding autolysin (lytA), pneumolysin, pneumococcal surface adhesin A, Spn9802, and capsular polysaccharides, detection of lytA appears to offer the highest specificity and sensitivity [102-104]. In this setting, detection of $l y t A$ is not only diagnostic, but also enables measurement of bacterial load, a determinant of disease severity and outcome [103]. More recently, several multiplex PCR procedures, both commercial and "in-house," have been developed which enable the simultaneous detection of a range of bacterial, as well as viral, respiratory pathogens [105-107]. However, application not only of these, but also the other aforementioned laboratory diagnostic procedures, should be tempered by an awareness of their limitations [108].

Sputum smear microscopy for the detection of acid-fast bacilli (AFB) and culture are the traditional, cornerstone, microbiological procedures for the laboratory diagnosis of tuberculosis (TB). Limitations of these procedures include a high frequency of smear-negativity, particularly in the setting of advanced 
immunosuppression in HIV infection [109-111], as well as the inability of microscopy to detect antibiotic resistance. Delayed acquisition of results is the major limitation of bacteriological culture procedures. The limitations of sputum smear microscopy, as well as those of radiographic confirmation, in patients coinfected with HIV and M.tuberculosis are underscored by the study of Chamie and colleagues [109]. These authors investigated the relationship between circulating $\mathrm{CD} 4^{+} \mathrm{T}$ cell counts and the diagnostic accuracy of AFB sputum smear microscopy and chest radiographs in HIVinfected African patients ( $n=873$ ) with culture-proven pulmonary TB. The mean percentages AFB sputum negativity were $23 \%$ and $1 \%$ in the sub-groups of patients with circulating $\mathrm{CD} 4^{+}$counts of $<50 / \mu \mathrm{l}$ and $>500 / \mu \mathrm{l}$ respectively, while the corresponding values for those with normal chest X-rays were $21 \%$ and $2 \%$ [109].

The limitations of traditional microbiological procedures for the detection of $M$. tuberculosis have largely been overcome by the integration into routine diagnostic services of the Xpert MTB/RIF, a fully automated, rapid, molecular diagnostic procedure [110,111]. Apart from improved sensitivity relative to sputum smear microscopy, together with a level of accuracy comparable with that of bacteriological culture, the Xpert MTB/RIF also enables simultaneous detection of rifampicin resistance $[110,111]$. It is particularly useful in the clinical setting of HIV/M. tuberculosis coinfection, especially in patients with advanced immunosuppression, as well as in patients with multidrug-resistant TB [110]. The Xpert MTB/RIF can also measure sputum bacillary load at diagnosis, a determinant of infectiousness and transmissibility [112].

In addition to detection of pathogen-specific antigens and/or nucleic acid, the adjunctive measurement of circulating host-derived biomarkers of inflammatory stress associated with microbial infection such as C-reactive protein, procalcitonin and cortisol, together with stable biomarkers of cardiovascular stress such as midregional adrenomedullin and copeptin, may be predictive of disease severity, response to therapy, and outcome [113,114]. 


\section{Antibiotic treatment}

While several guidelines describing the appropriate management of patients with CAP exist, there have been no reports specifically addressing the issue in HIVinfected patients [15]. The IDSA/ATS CAP guideline (2007) [115] recommends that in outpatients with underlying comorbid conditions or risk factors for antibioticresistant pneumococcal infections, as well as for cases hospitalized, but not in the ICU, antibiotic treatment should include a $\beta$-lactam together with a macrolide or a respiratory fluoroquinolone only, and many experts believe that this would also be appropriate for HIV-infected patients [15]. While a small retrospective study appeared to show no benefit of the addition of a macrolide to a beta-lactam agent above beta-lactam monotherapy in HIV infected patients with CAP [116], a large multicentre prospective observational study of patients with pneumococcal bacteremia documented a better outcome in patients treated with combination antibiotic therapy (most commonly the beta-lactam/macrolide combination) and this remained significant even when adjusted for HIV status [117].

\section{Severity of illness and outcome}

A number of studies have been undertaken determining whether various CAP severity of illness scores, or modifications of them, are able to accurately predict outcome in HIV-infected patients with CAP [118-121]. One study documented that the Pneumonia Severity Index (PSI) predicted 30-day mortality and need for ICU admission [120]. In that study, CD4 cell count did not predict patient outcome such that the authors concluded that the PSI could be used for mortality prediction at any level of immunosuppression. Another study, however, while documenting that a high PSI accurately predicted mortality, also noted that the mortality was significantly higher in patients with CD4 cell counts below 200 cells/ $\mu$ l [118]. These authors suggested that combining the CD4 cell count and PSI score may be a good strategy for deciding which HIV-infected patients with CAP needed hospital admission [118].

There is still considerable debate as to whether the clinical, laboratory and radiological features of CAP and the outcomes are different in HIV-infected and HIVuninfected cases. Studies have suggested that the clinical and radiological features 
of CAP are similar [122], and that there are no differences in time to clinical stability, length of hospitalization and mortality [123, 124]. Furthermore, it has also been documented that CD4 cell counts and HIV-RNA levels do not predict the likely outcomes in HIV-infected patients hospitalized with CAP [125]. In the case of bacteremic pneumococcal pneumonia in HIV-infected patients, while an earlier study suggested that there were no differences in clinical presentation and outcomes when comparing HIV-infected and HIV-uninfected patients [126], a more recent study reported not only that respiratory symptoms were more florid in HIV-infected patients, but when the data were adjusted for age and severity of illness, the HIVinfected patients had a higher 14-day mortality, with a significant trend for an increasing mortality as the CD4 cell count decreased [57]. Because of this finding, and in consideration of the findings by Curran and colleagues, described above [118], it has been suggested by some authors that a combined approach to severity assessment should be made and that all HIV-infected patients with CAP and a CD4 cell count below 200 cells $/ \mu$ should be admitted to hospital and in those with a CD4 cell count $>200$ cells $/ \mu$ l, the PSI could be used to direct need for hospital admission [15].

As in other medical conditions, it is not only HIV infection that impacts on the incidence, clinical features and outcome of CAP, but the occurrence of an episode of CAP has permanent effects on the human host and on the HIV course long-term. Thus one study showed that an episode of bacterial pneumonia (and also PCP) causes permanent decreases in lung function as measured by the $F E V_{1}, F V C$, $\mathrm{FEV}_{1} / \mathrm{FVC}$ ratio and diffusing capacity of carbon monoxide [127]. The authors suggest that while the clinical implications of this finding are unknown, they may be associated with prolonged respiratory symptoms after an episode of pneumonia. Furthermore, an additional study showed a significantly reduced median survival of HIV-infected patients following an episode of bacterial pneumonia (and also PCP) compared with median survival in control HIV-infected patients without an episode of bacterial pneumonia (24 months versus 37 months) [128]. Both these study findings emphasize the need for prevention of respiratory infections in HIV-infected persons. 


\section{Immunization strategies}

Of the aforementioned bacterial pathogens, immunization strategies are available for the prevention of pneumococcal infections. Two types of vaccine, both of which target the polysaccharide capsule, are currently in use. These are the pneumococcal polysaccharide vaccine, PPV23, and several types of pneumococcal conjugate vaccine (PCV) [129].

\section{Pneumococcal polysaccharide vaccine}

PPV23 is a cocktail consisting of capsular polysaccharides derived from 23 different serotypes of the pneumococcus which collectively account for $85-90 \%$ of cases of pneumococcal disease [130]. This vaccine elicits T-cell-independent antibody responses of the $\operatorname{lgG} / \operatorname{lgM}$ isotypes which promote opsonophagocytosis, with antibodies of the $\lg G 2$ subclass dominating the $\lg G$ response [131]. The vaccine also induces serotype-specific anti-capsular antibodies of the IgA class, promoting mucosal immunity [131]. Relative to PCVs, however, PPV23 exhibits poor immunogenicity in young children, does not affect nasopharyngeal colonization by the pneumococcus and induces only transient immunity in adults characterized by poor B cell memory, necessitating revaccination at 5-6 yearly intervals for individuals at particularly high risk, including those infected with HIV. This vaccination schedule is based on minimizing the potential risk of hyporesponsiveness associated with shorter intervals between revaccination. [130]. For similar reasons, the ACIP a maximum of two revaccinations with PPV23.

Current recommendations for immunization with PPV23 have been addressed in two recent, extensive reviews, both of which have highlighted the difficulties in establishing the efficacy of this vaccine, largely due to: i) poor immunogenicity; and ii) conflicting clinical trial data $[129,130]$. While there is consensus in support of the efficacy of PPV23 in conferring partial protection against IPD in older, immunocompetent adults, as well as younger individuals with predisposing illnesses who are not severely immunosuppressed, the vaccine is of limited efficacy in those at highest risk for development of IPD [129-131]. The efficacy of PPV23 in preventing non-invasive pneumococcal pneumonia and all-cause pneumonia is also 
an issue of contention, and may be influenced by factors such as a more rapid decline in post-vaccination mucosal, as opposed to systemic, immunity, as well as timing of vaccination and gender $[129,130]$.

Two very recent studies confirm the utility of PPV23 in preventing IPD in older adults, as well as its lack of efficacy in preventing all-cause pneumonia. In the first of these, a retrospective case-control study nested in a population-based cohort aged $\geq 65$ years ( $n=470070)$ covering a 4 year period, administration of PPV23 14 days 5 years prior to the index date conferred significant protection against development of IPD (42\% lower risk), but was ineffective in protecting against all-cause, hospitaltreated pneumonia [132]. In the second study, a randomized, double-blind, placebocontrolled trial involving young military trainees $(n=152723)$ followed for up to 6.7 years post-vaccination, administration of PPV23 had no protective effect on development of all-cause pneumonia [133]. Surprisingly, however, of the radiologically-confirmed cases of pneumonia reported during the study period $(n=371)$, none was caused by the pneumococcus [133].

Several retrospective studies have reported benefit of PPV23 in HIV-infected patients [134-136]. However, data from a number of other observational studies, as well as from a single randomized, double-blind trial conducted in Uganda, have failed to provide convincing evidence in support of a role for PPV23 in protecting against pneumococcal infections in HIV-infected patients with advanced immunosuppression [129, 130, 137]. Until fairly recently, however, the Advisory Committee on Immunization Practices (ACIP) of the Centers for Disease Control and Prevention of the USA continued to recommend administration of PPV23 with revaccination after an interval of 5 years for the prevention of IPD in the setting of HIV infection [138]. However, as addressed in more detail below, this recommendation has been superseded by a prime-boost strategy involving sequential administration of PCV13 and PPV23 [139].

\section{Pneumococcal conjugate vaccines}

The second type of pneumococcal vaccine is the pneumococcal conjugate vaccine (PCV) in which capsular polysaccharides derived from the most common disease- 
causing serotypes are conjugated to a non-toxic, immunogenic, carrier protein, usually the diphtheria toxoid, CMR197 [129, 130]. These vaccines, of which PCV13 is the current front-runner, having replaced its predecessors, PCV7 and PCV9, elicit a $T$ cell-dependent, anti-capsular polysaccharide antibody response and have several major advantages over PPV23 including [129, 130]:

- immunogenicity in neonates and children <2years of age

- prevention of nasopharyngeal colonization due to more effective mucosal immunity

- improved opsonophagocytic antibody responses, both qualitatively and quantitatively

- more durable antibody responses due to effective induction of memory B cells

- induction of indirect protection (herd immunity in adults, as well as nonvaccinated children).

Since its introduction in the USA in 2010 and integration into the national immunization programs of many other developed and developing countries thereafter, PPV13 has been reported to cause impressive decreases in the incidence of IPD caused by vaccine serotypes in children in the USA [140], France [141], England/Wales [142] and Mexico [143], as well as in adults due to indirect immunity [140-142]. With respect to immunization of adults, the Food and Drug Administration of the USA in late 2011 approved the use of PCV13 administered as a single dose to adults aged $\geq 50$ years to protect against pneumonia and IPD. In 2012, the ACIP recommended routine use of PCV13 for adults aged $\geq 19$ years with immunocompromising conditions, including HIV infection, functional or anatomic asplenia, cerebrospinal fluid leak, or cochlear implants using a prime-boost strategy [139]. This was based on primary immunization with PCV13 followed at least 8 weeks later by PPV23 [139]. More recently, based on early analysis of the results of the CAPITA trial [144], the ACIP recommended that PCV13 be used in combination with PPV23 in a similar prime-boost strategy with an interval of 6-12 months between immunizations in vaccine-naive subjects aged 65 years and older [145]. The CAPITA study demonstrated the efficacy of administration of a single dose of PCV13 to pneumococcal vaccine-naïve adults aged $\geq 65$ years $(n=84,496)$ in protecting against 
vaccine type pneumococcal pneumonia (45.6\%), vaccine type non-bacteremic pneumococcal pneumonia (45\%), and vaccine type IPD (75\%) [144].

With respect to the role of PCVs in preventing pneumococcal disease in those infected with HIV, immunization with PCV9 was found to decrease the incidence of a first episode of IPD due to vaccine serotypes in HIV-infected and -uninfected children by $65 \%$ and $83 \%$ respectively [146]. In a second study, the protective efficacy of administration of two doses of PCV7 administered 7 weeks apart to HIVinfected Malawian adults was found to protect against recurrent infection caused by vaccine serotypes, as well as against the non-vaccine serotype, 6A [147].

Although the efficacy of PCV13 in protecting HIV-infected remains to be established, the ACIP, as mentioned above, has recommended sequential administration of PCV13 and PPV23 in this setting [139]. This prime-boost strategy is based on the premise that "priming" (primary immunization) with a PCV, in this case PCV13, followed by secondary administration of PPV23 will significantly augment specific antibody responses to polysaccharide antigens common to both vaccines. Other advantages of the PCV13/PPV23 prime-boost strategy, include expanded coverage of vaccine serotypes, as well as reduction in the cost of immunization in certain environments.

\section{Prime-boost immunization for prevention of pneumococcal disease}

Evidence in support of this strategy is derived from two earlier studies, one undertaken in patients with treated Hodgkin's disease $(n=57)$ who received primary immunization with a variant of PCV7 known as 7-OMPC containing an outer membrane protein complex of Neisseria meningitides as carrier, followed by administration of PPV23 one year later [148]. In the second study, HIV-infected patients $(n=212)$ were randomized to receive primary immunization with PCV7 followed 4 weeks later by PPV23 and antibody responses to capsular polysaccharides measured pre-immunization and 8 weeks later relative to the responses of a control group immunized with a single dose of PPV23 [149]. In both studies, the prime-boost strategy resulted in significant augmentation of the concentrations of circulating $\lg G$ antibodies to 6 of the seven capsular 
polysaccharides common to both vaccines [148, 149]. However, similar prime-boost strategies undertaken in adult liver transplant patients (PCV7 followed 8 weeks later by PPV23) and Alaska Native adults aged 55-70 years (PCV7 followed 2-6 months later by PPV23) were found to be less effective $[150,151]$. In both studies, antibody responses to common serotypes induced by PCV7/PPV23 were comparable to those induced by PPV23 only [150, 151].

More recently, the efficacy of a re-vaccination strategy based on primary immunization with PCV13 or PPV23 followed by re-administration of either of these vaccines was evaluated in older adults aged 50-64 years in 2 different studies [152154]. In the first of these, two groups of adults aged 50-59 years $(n=214)$ and $60-64$ years ( $n=407$ ) previously immunized with either PCV13 (both age groups) or PPV23 (60-64 years only, $n=189$ ) when they were vaccine-naïve [152], were re-vaccinated 4 years later with PCV13 (younger group, PCV13/PCV13) or PPV (older group, PPV/PPV) [153]. Those in the older group who had originally received PCV13 were re-vaccinated with either PCV13 ( $n=108)$ or PPV23 (PCV13/PPV23, $n=108)$.

Concentrations of circulating functional, opsonophagocytic, anti-capsular antibodies were measured 4 weeks post-immunization. Relative to the responses following a first immunization with PPV23, post-immunization titers of opsonophagocytic antibodies in those who received PCV13/PPV23 were significantly higher for 10 of the serotypes common to both vaccines. Sequential immunization with PPV23, on the other hand, resulted in significantly decreased antibody titers to 9 of the common serotypes. Relative to the initial response to PCV13, sequential administration of PCV13 resulted in significantly improved antibody titers against 7 and 6 of the vaccine serotypes in the older and younger age groups respectively, with responses to the remaining serotypes being largely non-inferior [153].

In the second study, the efficacy of primary immunization with PCV13 followed 1 year later by secondary administration of PPV23 was evaluated in vaccine-naïve adults aged $60-64$ years $(n=720)$ [154]. Participants were randomized to receive PCV13/PPV23, or PPV23/PCV13, or PCV13/PCV13 with measurement of circulating, functional, opsonophagocytic anti-capsular antibodies undertaken before and 4 weeks after primary and secondary immunization. Initial immunization with PCV13 followed by PPV23 resulted in significant augmentation of opsonophagocytic 
antibody activities to 6 of the 12 common serotypes and non-inferior responses to the others relative to the corresponding responses following sequential administration of PPV23 [154]. When compared to the PPV23/PSV13 group, antibody responses were significantly higher to 11 of the 12 common serotypes. Sequential administration of PCV13 resulted in responses that were generally comparable to those following initial immunization, as well as being similar to, or somewhat lower, than those elicited following PCV13/PPV23 [154].

\section{Pneumococcal prime-boost immunization in HIV infection}

Although the efficacy of PCV13 in prevention of IPD in HIV-infected individuals has not been established, the ACIP, as mentioned above, currently recommends a routine prime-boost immunization strategy for immunocompromised adults aged $\geq 19$ years, encompassing HIV-infected persons [139]. This strategy entails primary immunization with PCV13 followed 8 weeks later by a single dose of PPV23, and revaccination with PPV23 after 5 years $[138,139]$, a recommendation supported by the findings of a recent study [155]. It is currently recommended for all vaccine-naïve HIV-infected persons. The possible exception is those subjects with circulating CD4 ${ }^{+}$ T cell counts of $<200 / \mu l$ blood. In this setting, it has been proposed that PPV23 be withheld until the circulating $\mathrm{CD} 4^{+} \mathrm{T}$ cell count recovers to levels above the threshold of 200 cells $/ \mu L$ [156]. This latter proposal is not, however, supported by a recent study which reported that post-immunization opsonophagocytic and immunoreactive antibody titers did not differ between groups of newly-diagnosed HIV-infected patients with CD4+ T cell counts of $<200 / \mu \mathrm{L}$ who were either immunized immediately with PPV23 or following 6-12 months of HAART [157]. Similar findings have been reported in HIV-infected patients with CD4+ counts of $\geq 200 / \mu \mathrm{l}$ [158]. Other aspects to be considered include the high percentage ( $15 \%)$ of HIV-infected individuals who do not achieve circulating CD4 ${ }^{+} T$ cell counts of $>200 / \mu \mathrm{L}$ despite several years of virally-suppressive HAART [159, 160], as well as the higher mortality rates within the first 3-12 months of treatment of HIV-positive patients living in low-income countries $[161,162]$.

A recent study has underscored the necessity for development of serotypeindependent, protein-based vaccines in the prevention of IPD in those infected with 
HIV. In this study, concentrations of circulating specific IgG antibodies to 27 pneumococcal protein antigens and 30 serotype capsular polysaccharides were measured before and $87 \pm 77.3$ and $183 \pm 97.5$ days post-IPD and compared with those of HIV-infected individuals without IPD [163]. In the IPD group, antibody responses to pneumococcal proteins were not only more frequent than those to capsular polysaccharides, but also persisted for longer, with PcpA, PsaA, and PiaA, the first two of which are priority protein vaccine candidates [129], being most immunogenic [163]. The IPD group also responded to a greater range of pneumococcal protein antigens than the control group. The finding that antibodies to pneumolysin were not detected is consistent with weak immunogenicity, underscoring the importance of development of vaccines which induce antibody responses to this major protein virulence factor of the pneumococcus [163].

Additional preventive measures include implementation of smoking screening and cessation strategies [164], as well as influenza immunization to counter the threat of pneumococcal infection [165-167], both of which should also be integrated into routine HIV care programs.

\section{Conclusions}

Despite all the advances there have been in the management of patients with HIV infection, it is clear when reviewing the literature that bacterial pneumonia, and in particular community-acquired pneumococcal pneumonia, remains globally a common problem among these patients, and is associated with considerable morbidity and mortality. Underlying HIV infection impacts on the frequency with which CAP occurs, even in the presence of HAART, its clinical manifestations and, at least in some cases, its outcome. Furthermore, an episode of CAP in HIV-infected persons is often followed by longer term consequences, including a lower mediumterm survival when compared to those who have not had an episode of pneumonia, as well as permanent declines in lung function parameters. It therefore remains important to prevent the occurrence of pneumonia in HIV-infected persons, which may be achieved through lifestyle changes and immunization strategies, with the pneumococcal conjugate vaccine playing an important role in the recommended vaccination practices. 
Acknowledgements: Charles Feldman is supported by the National Research Foundation (SA).

\section{References}

1. Mayaud C, Parrot A, Cadranel J. Pyogenic bacterial lower respiratory tract infection in human immunodeficiency virus-infected patients. Eur Respir J Suppl 2002; 20 (Suppl 36):28s-39s

2. Benito N, Moreno A, Miro JM, Torres A. Pulmonary infections in HIV-infected patients: an update in the 21st century. Eur Respir J 2012;39(3):730-745

3. Segal LN, Methé BA, Nolan A, et al. HIV -1 and bacterial pneumonia in the era of antiretroviral therapy. Proc Am Thorac Soc 2011;8(3):282-287

4. Brown J, Lipman M. Community-acquired pneumonia in HIV-infected individuals. Curr Infect Dis Rep 2014;16(3):397

5. Feldman C, Anderson R. HIV-associated bacterial pneumonia. Clin Chest Med 2013;34(2):205-216

6. Feldman C, Anderson R. Respiratory infections in specific populations: HIV patients. In: Blasi F, Dimopoulos G, eds. Textbook of Respiratory and Critical Care Infections. New Delhi, India: Jaypee Brothers Medical Publishers; 2015:139-158

7. Feikin DR, Feldman C, Schuchat A, Janoff EN. Global strategies to prevent bacterial pneumonia in adults with HIV disease. Lancet Infect Dis 2004;4(7):445455

8. Boschini A, Smacchia C, Di Fine M, et al. Community-acquired pneumonia in a cohort of former injection drug users with and without human immunodeficiency virus infection: incidence, etiologies, and clinical aspects. Clin Infect Dis 1996;23(1):107-113

9. Kohli R, Lo Y, Homel P, et al. Bacterial pneumonia, HIV therapy, and disease progression among HIV-infected women in the HIV epidemiologic research (HER) study. Clin Infect Dis 2006;43(1):90-98

10. Wolff AJ, O'Donnell AE. Pulmonary manifestations of HIV infection in the era of highly active antiretroviral therapy. Chest 2001;120(6):1888-1893 
11. Sullivan JH, Moore RD, Keruly JC, Chaisson RE. Effect of antiretroviral therapy on the incidence of bacterial pneumonia in patients with advanced HIV infection. Am J Respir Crit Care Med 2000;162(1):64-67

12. Hirschtick RE, Glassroth J, Jordan MC, et al. Bacterial pneumonia in persons infected with the human immunodeficiency virus. $\mathrm{N}$ Engl J Med 1995;333(13):845-851

13. Tumbarello M, Tacconelli E, de Gaetano K, et al. Bacterial pneumonia in HIVinfected patients: analysis of risk factors and prognostic indicators. J Acquir Immune Defic Syndr Hum Retrovirol 1998;18(1):39-45

14. Madeddu G, Porqueddu EM, Cambosu F, et al. Bacterial community acquired pneumonia in HIV-infected inpatients in the highly active antiretroviral therapy era. Infection 2008;36(3):231-236

15. Madeddu G, Laura Fiori M, Stella Mura M. Bacterial community-acquired pneumonia in HIV-infected patients. Curr Opin Pulm Med 2010;16(3):201-207

16. Mussini C, Galli L, Lepri AC, et al. Incidence, timing, and determinants of bacterial pneumonia among HIV-infected patients: data from the ICONA Foundation Cohort. J Acquir Immune Defic Syndr 2013;63(3):339-345

17. Penner J, Meier AS, Mwachari C, et al. Risk factors for pneumonia in urbandwelling HIV-infected women: a case-control in Nairobi, Kenya. J Acquir Immune Defic Syndr 2003;32(2):223-228

18. Navin TR, Rimland D, Lennox JL, et al. Risk factors for community-acquired pneumonia among persons infected with human immunodeficiency virus. J Infect Dis 2000;181(1):158-164

19. Bjerk SM, Baker JV, Emery S, et al. Biomarkers and bacterial pneumonia risk in patients with treated HIV infection: a case-control study. PLoS One 2013;8(2):e56249

20. Twigg HL 3rd, Knox KS. Impact of antiretroviral therapy on lung immunology and inflammation. Clin Chest Med 2013;34(2):155-164

21. Muson MA, Grobusch MP, van der Poll T. The effects of HIV infection on the host response to bacterial sepsis. Lancet Infect Dis 2015;15(1):95-108

22. Rossouw TM, Anderson R, Feldman C. Impact of HIV infection and smoking on lung immunity and related disorders. Eur Respir J (in press) 
23. Perreau M, Savoye AL, De Crignis E, et al. Follicular helper T cells serve as the major CD4 T cell compartment for HIV-1 infection, replication, and production. J Exp Med 2013;2(1):143-156

24. Jambo KC, Banda DH, Kankwatira AM, et al. Small alveolar macrophages are infected preferentially by HIV and exhibit impaired phagocytic function. Mucosal Immunol 2014;7(5):1116-1126

25. Gordon SB, Jagoe RT, Jarman ER, et al. The alveolar microenvironment of patients infected with human immunodeficiency virus does not modify alveolar macrophage interactions with Streptococcus pneumoniae. Clin Vaccine Immunol 2013;20(6):882-891

26. Malley R. Antibody and cell-mediated immunity to Streptococcus pneumoniae: implications for vaccine development. J Mol Med 2010;88(2):135-142

27. Crothers K, Griffith TA, McGinnis KA, et al. The impact of cigarette smoking on mortality, quality of life, and comorbid illness among HIV-positive veterans. J Gen Intern Med 2005;20(12):1142-1145

28. Feldman JG, Minkoff H, Schneider MF, et al. Association of cigarette smoking with HIV prognosis among women in the HAART era: a report from the women's interagency HIV study. Am J Public Health 2006;96(6):1060-1065

29. Gordin FM, Roediger MP, Girard P-M, et al. Pneumonia in HIV-infected persons: Increased risk with cigarette smoking and treatment interruption. Am J Respir Crit Care Med 2008;178(6):630-636

30. Petrosillo N, Cicalini S. Smoking and HIV: time for a change? BMC Med 2013;11:16

31. Helleberg M, Afzal S, Kronborg G, et al. Mortality attributable to smoking among HIV-1-infected individuals: a nationwide, population-based cohort study. Clin Infect Dis 2013;56(5):727-734

32. Feldman C, Anderson R. Cigarette smoking and mechanisms of susceptibility to infections of the respiratory tract and other organ systems. J Infect 2013;67(3):169-184

33. Sapkota AR, Berger S, Vogel TM. Human pathogens abundant in the bacterial metagenome of cigarettes. Environ Health Perspect 2010;118(3):351-356

34. Brook I, Gober AE. Recovery of potential pathogens and interfering bacteria in the nasopharynx of smokers and nonsmokers. Chest 2005;127(6):2072-2075 
35. Voss M, Wonnenberg B, Honecker A, et al. Cigarette smoke-promoted acquisition of bacterial pathogens in the upper respiratory tract leads to enhanced inflammation in mice. Respir Res 2015;16(1):41

36. Kulkarni R, Antala S, Wang A, et al. Cigarette smoke increases Staphylococcus aureus biofilm formation via oxidative stress. Infect Immun 2012;80(11):38043811

37. Mutepe ND, Cockeran R, Steel HC, et al. Effects of cigarette smoke condensate on pneumococcal biofilm formation and pneumolysin. Eur Respir $\mathrm{J}$ 2013;41(2):392-395

38. Hutcherson JA, Scott DA, Bagaitkar J. Scratching the surface - tobacco-induced bacterial biofilms. Tob Induc Dis 2015;13(1):1

39. Kearley J, Silver JS, Sanden C, et al. Cigarette smoke silences innate lymphoid cell function and facilitates an exacerbated type I interleukin-33-dependent response to infection. Immunity 2015;42(3):566-579

40. Bourdonnay E, Zasłona Z, Penke LR, et al. Transcellular delivery of vesicular SOCS proteins from macrophages to epithelial cells blunts inflammatory signaling. J Exp Med 2015;212(5):729-742

41. Grigg J, Walters $\mathrm{H}$, Sohal SS, et al. Cigarette smoke and platelet-activating factor receptor dependent adhesion of Streptococcus pneumoniae to lower airway cells. Thorax 2012;67(10):908-913

42. Schamberger AC, Mise N, Jia J, et al. Cigarette smoke-induced disruption of bronchial epithelial tight junctions is prevented by transforming growth factor- $\beta$. Am J Respir Cell Mol Biol 2014;50(6):1040-1052

43. Lozupone C, Cota-Gomez A, Palmer BE, et al. Widespread colonization of the lung by Tropheryma whipplei in HIV infection. Am J Respir Crit Care Med 2013;187:1110-1117

44. Cui L, Lucht $L$, Tipton $L$, et al. Topographic diversity of the respiratory tract mycobiome and alteration in HIV and lung disease. Am J Respir Crit Care Med 2015;191(8):932-942

45. Morris A, Beck JM, Schloss PD, et al. Comparison of the respiratory microbiome in healthy nonsokers and smokers. Am J Respir Crit Care Med 2013;187(10):1067-1075

46. Sopena N, Pedro-Botet ML, Sabrià M, García-Parés D, Reynaga E, GarcíaNuñez M. Comparative study of community-acquired pneumonia caused by 
Streptococcus pneumoniae, Legionella pneumophila or Chlamydia pneumoniae. Scand J Infect Dis 2004;36(5):330-334

47. Chidiac $\mathrm{C}$. Pneumococcal infections and adult with risk factors. Med Mal Infect 2012;42(10):517-524

48. Kyaw MH, Rose CE Jr, Fry AM, et al. The influence of chronic illnesses on the incidence of invasive pneumococcal disease in adults. $J$ Infect Dis 2005;192(3):377-386

49. Lynch JP III, Zhanel GG. Streptococcus pneumoniae: epidemiology, risk factors, and strategies for prevention. Semin Respir Crit Care Med 2009;30(2):189-209

50. Mufson MA, Hao JB, Stanek RJ, Norton NB. Clinical features of patients with recurrent invasive Streptococcus pneumoniae disease. Am J Med Sci 2012;343(4):303-309

51. Dworkin MS, Ward JW, Hanson DL, Jones JL, Kaplan JE; Adult and Adolescent Spectrum of HIV Disease Project. Pneumococcal disease among human immunodeficiency virus-infected persons: incidence, risk factors, and impact of vaccination. Clin Infect Dis 2001;32(5):794-800

52. Perelló R, Miró O, Marcos MA, et al. Predicting bacteremic pneumonia in HIV-1infected patients consulting the ED. Am J Emerg Med 2010;28(4):454-459

53. Munier AL, de Lastours V, Porcher R, Donay JL, Pons JL, Molina JM . Risk factors for invasive pneumococcal disease in HIV-infected adults in France in the highly active antiretroviral therapy era. Int J STD AIDS 2014;25(14):1022-1028

54. Jover F, Cuadrado JM, Andreu L, et al. A comparative study of bacteremic and non-bacteremic pneumococcal pneumonia. Eur J Intern Med 2008;19(1):15-21

55. Yin Z, Rice BD, Waight $P$, et al. Invasive pneumococcal disease among HIVpositive individuals, 2000-2009. AIDS 2012;26(1):87-94

56. Madeddu G, Fois AG, Pirina P, Mura MS. Pneumococcal pneumonia: clinical features, diagnosis and management in HIV-infected and HIV noninfected patients. Curr Opin Pulm Med 2009;15(3):236-242

57. Feldman C, Klugman KP, Yu VL, et al. Bacteraemic pneumococcal pneumonia: impact of HIV on clinical presentation and outcome. J Infect 2007;55(2):125-135

58. Schleicher GK, Feldman C. Dual infection with Streptococcus pneumoniae and Mycobacterium tuberculosis in HIV-seropositive patients with community acquired pneumonia. Int J Tuberc Lung Dis 2003;7(12):1207-1208 
59. Sanz JC, Cercenado E, Marin M, et al. Multidrug-resistant pneumococci (serotype 8) causing invasive disease in HIV+ patients. Clin Microbiol Infect 2011;17(7):1094-1098

60. Isea-Peña MC, Sanz-Moreno JC, Esteban J, Fernández-Roblas R, FernándezGuerrero ML. Risk factors and clinical significance of invasive infections caused by levofloxacin-resistant Streptococcus pneumoniae. Infection 2013;41(5):935939

61. Allen SH, Brennan-Benson P, Nelson M, et al. Pneumonia due to antibiotic resistant Streptococcus pneumoniae and Pseudomonas aeruginosa in the HAART era. Postgrad Med J 2003;79(938):691-694

62. Jordano Q, Falcó $\mathrm{V}$, Almirante $\mathrm{B}$, et al. Invasive pneumococcal disease in patients infected with HIV: still a threat in the era of highly active antiretroviral therapy. Clin Infect Dis 2004;38(11):1623-1628

63. Heffernan RT, Barrett NL, Gallagher KM, et al. Declining incidence of invasive Streptococcus pneumoniae infections among persons with AIDS in an era of highly active antiretroviral therapy, 1995-2000. J Infect Dis 2005;191(12):20382045

64. Saindou M, Chidiac C, Miailhes $P$, et al. Pneumococcal pneumonia in HIVinfected patients by antiretroviral therapy periods. HIV Med 2008;9(4):203-207

65. Siemieniuk RAC, Gregson DB, Gill MJ. The persisting burden of invasive pneumococcal disease in HIV patients: an observational cohort study. BMC Infect Dis $2011 ; 11: 314$

66. Nunes MC, von Gottberg A, de Gouveia L, et al. Persistent high burden of invasive pneumococcal disease in South African HIV-infected adults in the era of an antiretroviral treatment program. PLoS One 2011;6(11):e27929

67. Falcó V, Burgos J, Pahissa A. The spectrum of invasive pneumococcal disease in adults in the XXI century. Clin Pulm Med 2013;20(5):214-220

68. Schlamm HT, Yancovitz SR. Haemophilus influenzae pneumonia in young adults with AIDS, ARC, or risk of AIDS. Am J Med 1989;86(1):11-14

69. Moreno S, Martinez R, Barros C, Gonzalez-Lahoz J, Garcia-Delgado E, Bouza E. Latent Haemophilus influenzae pneumonia in patients infected with HIV. AIDS 1991;5(8):967-970 
70. Casadevall A, Dobroszycki J, Small C, Pirofski LA. Haemophilus influenzae type $\mathrm{b}$ bacteremia in adults with AIDS and at risk for AIDS. Am J Med 1992;92(6):587590

71. Rich JD, Sax PE, Kazanjian PH, Brigham. Bacteremic H. influenzae type b infections and HIV. Am J Med 1993;95(1):118-119

72. Muñoz P, Miranda ME,Llancaqueo A, Peláez T, Rodríguez-Créixems M, Bouza E. Haemophilus species bacteremia in adults. The importance of the human immunodeficiency virus epidemic. Arch Intern Med 1997;157(16):1869-1873

73. Cordero E, Pachón J, Rivero A, et al. Haemophilus influenzae pneumonia in human immunodeficiency virus-infected patients. Clin Infect Dis 2000;30(3):461465

74. Levine SJ, White DA, Fels AO. The incidence and significance of Staphylococcus aureus in respiratory cultures from patients infected with the human immunodeficiency virus. Am Rev Respir Dis 1990;141(1):89-93

75. Tumbarello M, Tacconelli E, Lucia MB, Cauda R, Ortona L. Predictors of Staphylococcus aureus pneumonia associated with human immunodeficiency virus infection. Respir Med 1996;90(9):531-537

76. Gil Suay V, Cordero PJ, Martinez E, et al. Parapneumonic effusions secondary to community-acquired bacterial pneumonia in human immunodeficiency virusinfected patients. Eur Respir J 1995;8(11):1934-1939

77. Lobo LJ, Reed KD, Wunderink RG. Expanded clinical presentation of communityacquired methicillin-resistant Staphylococcus aureus pneumonia. Chest 2010;138(1):130-136

78. Daneshvar C, Smith NC, Waghorn DJ, Luzzi GA, Wathen CG. Communityacquired pneumonia due to Panton-Valentine leukocidin-producing Staphylococcus aureus in an HIV-2-infected patient. Int J STD AIDS 2011;22(10):610-612

79. Tarp B, Jensen JS, Ostergaard L, Andersen PL. Search for agents causing atypical pneumonia in HIV-positive patients by inhibitor-controlled PCR assays. Eur Respir J 1999;13(1):175-179

80. Sandkovsky U, Sandkovsky G, Suh J, Smith B, Sharp V, Polsky B. Legionella pneumophila pneumonia and HIV: case reports and review of the literature. AIDS Patient Care and STDS 2008;22(6):473-481 
81. Pedro-Botet ML, Sabrià M, Sopena N, et al. Legionnaires disease and HIV infection. Chest 2003;124(2):543-547

82. Robbins NM, Kumar A, Blair BM. Legionella pneumophila infection presenting as headache, confusion and dysarthria in a human immunodeficiency virus-1 (HIV1) positive patient: case report. BMC Infect Dis 2012;12:225

83. Comandini UV, Maggi P, Santopadre P, Monno R, Angarano G, Vullo V. Chlamydia pneumoniae respiratory infections among patients infected with the human immunodeficiency virus. Eur J Clin Microbiol Infect Dis 1997;16(10):720726.

84. Tositti G, Rassu M, Fabris P, et al. Chlamydia pneumoniae infection in HIVpositive patients: prevalence and relationship with lipid profile. HIV Med 2005;6(1):27-32

85. Shankar EM, Kumarasamy N, Vignesh R, et al. Epidemiological studies on pulmonary pathogens in HIV-positive and -negative subjects with or without community-acquired pneumonia with special emphasis on Mycoplasma pneumoniae. Jpn J Infect Dis 2007;60(6):337-341

86. Ali NJ, Kessel D, Miller RF. Bronchopulmonary infection with Pseudomonas aeruginosa in patients infected with human immunodeficiency virus. Genitourin Med 1995;71(2):73-77

87. Meynard JL, Barbut $F$, Guiguet M, et al. Pseudomonas aeruginosa infection in human immunodeficiency virus infected patients. J Infect 1999;38(3):176-181

88. Afesssa B, Green B. Bacterial pneumonia in hospitalized patient with HIV infection: the Pulmonary Complications, ICU Support, and Prognostic Factors of Hospitalized Patients with HIV (PIP) Study. Chest 2000;117(4):1017-1022

89. Manfredi R, Nanetti A, Ferri M, Chiodo F. Pseudomonas spp. complications in patients with HIV disease: an eight-year clinical and microbiological survey. Eur J Epidemiol 2000;16(2):111-118

90. Sadikot RT, Blackwell TS, Christman JW, Prince AS. Pathogen-host interactions in Pseudomonas aeruginosa pneumonia. Am J Respir Crit Care Med 2005;171(11):1209-1223

91. Williams BJ, Dehnbostel J, Blackwell TS. Pseudomonas aeruginosa: host defence in lung diseases. Respirology 2010;15(7):1037-1056 
92. Fujitani S, Sun HY, Yu VL, Weingarten JA. Pneumonia due to Pseudomonas aeruginosa: part I: epidemiology, clinical diagnosis, and source. Chest 2011;139(4):909-919

93. Topino S, Galati V, Grilli E, Petrosillo N. Rhodococcus equi infection in HIVinfected individuals: case reports and review of the literature. AIDS Patient Care and STDS 2010;24(4):211-222

94. Manfredi R, Nanetti A, Valentini R, Chiodo F. Moraxella catarrhalis pneumonia during HIV disease. J Chemother 2000;12(5):406-411

95. Smith MD, Derrington P, Evans R, et al. Rapid diagnosis of bacteremic pneumococcal infections in adults by using the Binax NOW Streptococcus pneumoniae urinary antigen test: a prospective, controlled clinical evaluation. $\mathrm{J}$ Clin Microbiol 2003;41(7):2810-2813

96. Jørgensen CS, Uldum SA, Sørensen JF, Skovsted IC, Otte S, Elverdal PL. Evaluation of a new lateral flow test for detection of Streptococcus pneumoniae and Legionella pneumophila urinary antigen. J Microbiol Methods 2015;116:3336 [Epub ahead of print]

97. Sheppard CL, Harrison TG, Smith MD, George RC. Development of a sensitive, multiplexed immunoassay using XMAP beads for detection of serotype-specific Streptococcus pneumoniae antigen in urine samples. J Med Microbiol 2011;60(Pt 1):49-55

98. Pride MW, Huijts SM, Wu K, et al. Validation of an immunodiagnostic assay for detection of 13 Streptococcus pneumoniae serotype-specific polysaccharides in human urine. Clin Vaccine Immunol 2012;19(8):1131-1141

99. Elberse K, van Mens S, Cremers AJ, et al. Detection and serotyping of pneumococci in community acquired pneumonia patients without culture using blood and urine samples. BMC Infect Dis 2015;15:56

100. Slotved HC, Kaltoft M, Skovsted IC, Kerrn MB, Espersen F. Simple, rapid latex agglutination test for serotyping of pneumococci (Pneumotest-Latex). J Clin Microbiol 2004;42(6):2518-2522

101. Kuch A, Gołębiewska A, Waśko I, et al. Usefulness of Pneumotest-Latex for direct serotyping of Streptococcus pneumoniae isolates in clinical samples. J Clin Microbiol 2014;52(7):2647-2649 
102. Carvalho MdaG, Tondella ML, McCaustland K, et al. Evaluation and improvement of real-time PCR assays targeting $l y t A$, ply, and $p s a A$ genes for detection of pneumococcal DNA. J Clin Microbiol 2007;45(8):2460-2466

103. Werno AM, Anderson TP, Murdoch DR. Association between pneumococcal load and disease severity in adults with pneumonia. J Med Microbiol 2012;61(Pt 8):1129-1135

104. Strålin K, Herrmann B, Adeldaim G, Olcén P, Holmberg H, Mölling P. Comparison of sputum and nasopharyngeal aspirate samples and of the PCR gene targets lytA and Spn9802 for quantitative PCR for rapid detection of pneumococcal pneumonia. J Clin Microbiol 2014;52(1):83-89

105. Bogaerts $\mathrm{P}$, Hamels $\mathrm{S}$, de Mendonca $\mathrm{R}$, et al. Analytical validation of a novel high multiplexing real-time PCR array for the identification of key pathogens causative of bacterial ventilator-associated pneumonia and their associated resistance genes. J Antimicrob Chemother 2013;68(2):340-347

106. Jamal W, Al Roomi E, AbdulAziz LR, Rotimi VO. Evaluation of Curetis Unyvero, a multiplex PCR-based testing system, for rapid detection of bacteria and antibiotic resistance and impact of the assay on management of severe nosocomial pneumonia. J Clin Microbiol 2014;52(7):2487-2492

107. Gadsby NJ, McHugh MP, Russell CD, et al. Development of two real-time multiplex PCR assays for the detection and quantification of eight key bacterial pathogens in lower respiratory tract infection. Clin Microbiol Infect 2015;21(8):788

108. Jain $\mathrm{S}$, Self $\mathrm{WH}$, Wunderink RG, et al. Community-acquired pneumonia requiring hospitalization among U.S. adults. N Engl J Med 2015 [Epub ahead of print]

109. Chamie G, Luetkemeyer A, Walusimbi-Nanteza M, et al. Significant variation in presentation of pulmonary tuberculosis across a high resolution of CD4 strata. Int J Tuberc Lung Dis 2010;14(10):1295-1302

110. Piatek AS, van Cleeff M, Alexander $\mathrm{H}$, et al. GeneXpert for TB diagnosis: planned and purposeful implementation. Glob Health Sci Pract 2013;1(1):18-23

111. Theron G, Peter J, van Zyl-Smit R, et al. Evaluation of the Xpert MTB/RIF assay for the diagnosis of pulmonary tuberculosis in a high HIV prevalence setting. Am J Respir Crit Care Med 2011;184(1):132-140

112. Hanrahan $\mathrm{CF}$, Theron $\mathrm{G}$, Bassett $\mathrm{J}$, et al. Xpert MTB/RIF as a measure of sputum bacillary burden. Am J Respir Crit Care Med 2014;189(11):1426-1434 
113. Florin TA, Ambroggio L. Biomarkers for community-acquired pneumonia in the emergency department. Clin Infect Dis Rep 2014;16(12):451

114. Kolditz M, Ewig S, Höffken G. Management-based risk prediction in community-acquired pneumonia by scores and biomarkers. Eur Respir $\mathrm{J}$ 2013;41(4):974-984

115. Mandell LA, Wunderink RG, Anzueto A, et al. Infectious Diseases Society of America/American Thoracic Society consensus guidelines on the management of community-acquired pneumonia in adults. Clin Infect Dis 2007;44(Suppl 2):S27S72

116. Mello CF, Negra MD. Impact of macrolide therapy on mortality of HIV-infected patients with community-acquired pneumonia in a tertiary teaching hospital. Braz $\mathrm{J}$ Infect Dis 2011;15(3):262-267

117. Baddour LM, Yu VL, Klugman KP, et al. Combination antibiotic therapy lowers mortality among severely ill patients with pneumococcal bacteremia. Am J Respir Crit Care Med 2004;170(4):440-444

118. Curran A, Falcó V, Crespo M, et al. Bacterial pneumonia in HIV-infected patients: use of the pneumonia severity index and impact of current management on incidence, aetiology and outcome. HIV Medicine 2008;9(8):609-615

119. Cordero E, Pachón J, Rivero A, et al. Community-acquired bacterial pneumonia in human immunodeficiency virus-infected patients: validation of severity criteria. Am J Respir Crit Care Med 2000;162(6):2063-2068

120. Chew KW, Yen IH, Li JZ, Winston LG. Predictors of pneumonia severity in HIV-infected adults admitted to an urban public hospital. AIDS Patient Care and STDS 2011;25(5):273-277

121. Barakat $L A$, Juthani-Mehta $M$, Allore $H$, et al. Comparing clinical outcomes in HIV-infected and uninfected older men hospitalized with community-acquired pneumonia. HIV Med 2015;16(7):421-430

122. Yone EW, Balkissou AD, Kengne AP, Kuaban C. Influence of HIV infection on the clinical presentation and outcome of adults with acute community-acquired pneumonia in Yaounde, Cameroon: a retrospective hospital-based study. BMC Pulm Med 2012;12:46.

123. Christensen D, Feldman C, Rossi P, et al. HIV infection does not influence clinical outcomes in hospitalized patients with bacterial community-acquired 
pneumonia: results from the CAPO international cohort study. Clin Infect Dis 2005;41(4):554-556

124. Malinis M, Myers J, Bordon J, et el. Clinical outcomes of HIV-infected patients hospitalized with bacterial community-acquired pneumonia. Int $\mathrm{J}$ Infect Dis 2010;14(1):e22-e27

125. Bordon J, Kapoor R, Martinez C, et al. CD4+ counts and HIV-RNA levels do not predict outcomes of community-acquired pneumonia in hospitalized HIVinfected patients. Int J Infect Dis 2011;15(12):e822-e827

126. Feldman C, Glatthaar M, Morar R, et al. Bacteremic pneumococcal pneumonia in HIV-seropositive and HIV-seronegative adults. Chest 1999;116(1):107-114

127. Morris $A M$, Huang $L$, Bacchetti $P$, et al. Permanent declines in pulmonary function following pneumonia in human immunodeficiency virus-infected persons. Am J Respir Crit Care Med 2000;162(2 Pt 1):612-616

128. Osmond DH, Chin DP, Glassroth J, et al. Impact of bacterial pneumonia and Pneumocystis carinii pneumonia on human immunodeficiency virus disease progression. Clin Infect Dis 1999;29(3):536-543

129. Feldman $C$, Anderson R. Review: Current and new generation pneumococcal vaccines. J Infect 2014;69(4):309-325

130. Musher DM. Pneumococcal vaccination in adults. UpToDate; April 2015, www.uptodate.com

131. WHO. Pneumococcal polysaccharide vaccine. WHO position paper; March 2008, http://www.who.int/immunization/sage/1 PPV23 draft March 3 clean.pdf

132. Leventer-Roberts M, Feldman BS, Brufman I, Cohen-Stavi CJ, Hoshen M, Balicer RD. Effectiveness of 23-valent pneumococcal polysaccharide vaccine against invasive disease and hospital-treated pneumonia among people aged $\geq 65$ years: a retrospective case-control study. Clin Infect Dis 2015;60(10):14721480

133. Russel KL, Baker Cl, Hansen C, et al. Lack of effectiveness of the 23-valent polysaccharide pneumococcal vaccine in reducing all-cause pneumonias among healthy young military recruits: a randomized, double-blind, placebo-controlled trial. Vaccine 2015;33(9):1182-1187 
134. Peñaranda $M$, Falco $V$, Payeras $A$, et al. Effectiveness of polysaccharide pneumococcal vaccine in HIV-infected patients: A case-control study. Clin Infect Dis $2007 ; 45(7): 82-87$

135. Rodriguez-Barradas MC, Goulet J, Brown S, et al. Impact of pneumococcal vaccination on the incidence of pneumonia by HIV infection status among patients enrolled in the Veterans Aging Cohort 5-Site Study. Clin Infect Dis 2008; 46(7):1093-1100

136. Imaz A, Falco V, Peñaranda M, et al. Impact of prior pneumococcal vaccination on clinical outcomes in HIV-infected adult patients hospitalized with invasive pneumococcal disease. HIV Med 2009;10(6):356-363

137. French N, Nakiyingi J, Carpenter LM, et al. 23-Valent pneumococcal polysaccharide vaccine in HIV-1-infected Ugandan adults: double-blind, randomised and placebo controlled trial. Lancet 2000;355(9221):2106-2111

138. Centers for Disease Control and Prevention (CDC). Updated recommendations for prevention of invasive pneumococcal disease among adults using the 23-valent pneumococcal polysaccharide vaccine (PPSV23). MMWR Morb Mortal Wkly Rep 2010;59(34):1102-1106

139. Centers for Disease Control and Prevention (CDC). Use of 13-valent pneumococcal conjugate vaccine and 23-valent pneumococcal polysaccharide vaccine for adults with immunocompromising conditions: recommendations of the advisory committee on immunization practices (ACIP). MMWR Morb Mortal Wkly Rep 2012;61(40):816-819

140. Moore MR, Link-Gelles R, Schaffner W, et al. Effect of use of 13-valent pneumococcal conjugate vaccine in children on invasive pneumococcal disease in children and adults in the USA: analysis of multisite, population-based surveillance. Lancet Infect Dis 2015;15(3):301-309

141. Lepoutre A, Varon E, Georges S, et al. Impact of the pneumococcal conjugate vaccines on invasive pneumococcal disease in France, 2001-2012. Vaccine 2015;33(2):359-366

142. Waight PA, Andrews NJ, Ladhani SN, Sheppard CL, Slack MP, Miller E. Effect of the 13-valent pneumococcal conjugate vaccine on invasive pneumococcal disease in England and Wales 4 years after its introduction: an observational cohort study. Lancet Infect Dis 2015;15(5):535-543 
143. Chacon-Cruz E, Rivas-Landeros RM, Volker-Soberanes ML. Early trends in invasive pneumococcal disease in children following the introduction of 13-valent pneumococcal conjugate vaccine: results from eight years of active surveillance in a Mexican hospital. Ther Adv Vaccines 2014;2(6):155-158

144. Bonten MJ, Huijts SM, Bolkenbaas M, et al. Polysaccharide conjugate vaccine against pneumococcal pneumonia in adults. N Engl J Med 2015;372(12):11141125

145. Centers for Disease Control and Prevention (CDC). Use of 13-valent pneumococcal conjugate vaccine and 23-valent pneumococcal polysaccharide vaccine among adults aged $\geq 65$ years: recommendations of the advisory committee on immunization practices (ACIP). MMWR Morb Mortal Wkly Rep 2014;63(37):822-825

146. Klugman KP, Madhi SA, Huebner RE, Kohberger R, Mbelle N, Pierce N. A trial of a 9-valent pneumococcal conjugate vaccine in children with and those without HIV infection. N Engl J Med 2003;349(14):1341-1348

147. French N, Gordon SB, Mwalukomo T, et al. A trial of a 7-valent pneumococcal conjugate vaccine in HIV-infected adults. N Engl J Med 2010;362(9):812-822

148. Chan CY, Molrine DC, George S, et al. Pneumococcal conjugate vaccine primes for antibody responses to polysaccharide pneumococcal vaccine after treatment of Hodgkin's Disease. J Infect Dis 1996;173(1):256-258

149. Lesprit P, Pédrono G, Molina JM, et al. Immunological efficacy of a primeboost pneumococcal vaccination in HIV-infected adults. AIDS 2007;21(18):24252434

150. Kumar D, Chen MH, Wong G, et al. A randomized, double-blind, placebocontrolled trial to evaluate the prime-boost strategy for pneumococcal vaccination in adult liver transplant recipients. Clin Infect Dis 2008;47(7):885-892

151. Miernyk KM, Butler JC, Bulkow LR, et al. Immunogenicity and reactogenicity of pneumococcal polysaccharide and conjugate vaccines in Alaska Native adults 55-70 years of age. Clin Infect Dis 2009;49(2):241-248

152. Jackson LA, Gurtman A, van Cleeff M, et al. Immunogenicity and safety of a 13-valent pneumococcal conjugate vaccine compared to a 23-valent pneumococcal polysaccharide vaccine in pneumococcal vaccine-naïve adults. Vaccine 2013;31(35):3577-3584 
153. Jackson LA, Gurtman A, van Cleeff M, et al. Influence of initial vaccination with 13-valent pneumococcal conjugate vaccine or 23-valent pneumococcal polysaccharide vaccine on anti-pneumococcal responses following subsequent pneumococcal vaccination in adults 50 years and older. Vaccine 2013;31(35):3594-3602

154. Greenberg RN, Gurtman A, Frenck RW, et al. Sequential administration of 13valent pneumococcal conjugate vaccine and 23-valent pneumococcal polysaccharide vaccine in pneumococcal vaccine-naïve adults 60-64 years of age. Vaccine 2014;32(20):2364-2374

155. Iyer AS, Leggat DJ, Ohtola JA, et al. Response to pneumococcal polysaccharide vaccination in HIV-positive individuals on long term highly active antiretroviral therapy. J AIDS Clin Res 2015;6(2):421

156. Hibberd PL. Immunizations in HIV-infected patients. UpToDate; May 2015; www.uptodate.com

157. Leggat DJ, lyer AS, Ohtola JA, et al. Response to pneumococcal polysaccharide vaccination in newly diagnosed HIV-positive individuals. J AIDS Clin Res 2015;6(2):419

158. Rodriguez-Barradas MC, Serpa JA, Munjal I, et al. Quantitative and qualitative antibody responses to immunization with the pneumococcal polysaccharide vaccine in HIV-infected patients after initiation of antiretroviral treatment: results from a randomized clinical trial. J Infect Dis 2015;211(11):1703-1711

159. Engsig FN, Zangerle R, Katsarou O, et al. Long-term mortality in HIV-positive individuals virally suppressed for $>3$ years with incomplete CD4 recovery. Clin Infect Dis 2014;58(9):1312-1321

160. Zoufaly A, Cozzi-Lepri A, Reekie J, et al. Immuno-virological discordance and the risk of non-AIDS and AIDS events in a large observational cohort of HIVpatients in Europe. PLoS One 2014;9(1):e87160

161. Braitstein P, Brinkhof MW, Dabis F, et al. Mortality of HIV-1-infected patients in the first year of antiretroviral therapy: comparison between low-income and high-income countries. Lancet 2006;367(9513):817-824

162. Keiser O, Orrell C, Egger M, et al. Public-health and individual approaches to antiretroviral therapy: township South Africa and Switzerland compared. PLoS Med 2008;5(7):e148 
163. Kantsø B, Green N, Goldblatt D, Benfield T. Antibody response is more likely to pneumococcal proteins than to polysaccharide after HIV-associated invasive pneumococcal disease. J Infect Dis 2015. [Epub ahead of print]

164. Mdodo R, Frazier EL, Dube SR, et al. Cigarette smoking prevalence among adults with HIV compared with the general population in the United States. Ann Intern Med 2015;162(5):335-344

165. McCullers JA. Insights into the interaction between influenza virus and pneumococcus. Clin Microbiol Rev 2006;19(3):571-582

166. Remschmidt C, Wichmann O, Harder T. Influenza vaccination in HIV-infected individuals:Systematic review and assessment of quality of evidence related to vaccine efficacy, effectiveness and safety. Vaccine 2014;32(43 ):5585-5592

167. Cohen C, Moyes J, Tempia S, et al. Mortality amongst patients with influenza-associated severe acute respiratory illness, South Africa, 2009-2013. PLoS One 2015;10(3):e0118884 